\title{
Grupos de investigação em educação superior: por onde anda a produção do conhecimento científico?
}

\author{
Research groups in higher education: where is the production of scientific \\ knowledge?
}

Grupos de investigación en educación superior: ¿por dónde anda la producción del conocimiento cientifico?

\begin{abstract}
Maria de Lourdes Pinto Almeida ${ }^{1}$
Universidade do Oeste de Santa Catarina, Docente Pesquisadora do Programa de PósGraduação em Educação; Rede Iberoamericana de Estudos e Pesquisas em Políticas e

Processos de Educação Superior, Diretora
\end{abstract}

\section{Fernando Rodrigo Dall Igna ${ }^{2}$}

Secretaria de Educação do Estado de Santa Catarina, Professor da Rede Estadual de Ensino de Chapecó; Grupo de Estudos e Pesquisas em Políticas de Educação Superior da Região Sul, Pesquisador

Resumo: No artigo apresenta-se, a partir de um mapeamento, o perfil dos grupos de pesquisa em educação superior cadastrados no Diretório de Pesquisa do Conselho Nacional de Desenvolvimento Científico e Tecnológico (CNPq) em universidades públicas da região Sul do Brasil. A investigação é bibliográfica e documental, tendo como metodologia de análise a histórico-crítica. As discussões contribuem para identificar os eixos temáticos que caminham à produção do conhecimento científico via pesquisa na educação superior no Brasil, destacando como consequência a efetiva e tão discutida ideia de (re)produtivismo acadêmico em nível mundial e suas repercussões no Brasil.

Palavras-chave: Grupos de pesquisa em educação superior. Políticas de educação superior. Produção do conhecimento no ensino superior.

\footnotetext{
Pós-doutora em Políticas Educacionais pela Universidade de São Paulo; Pós-doutora em Ciência, Tecnologia e Sociedade pela Universidade Estadual de Campinas; Doutora em Educação pela Universidade Estadual de Campinas.

2 Pós-graduado em Educação Integral pela Universidade Federal da Fronteira Sul; mestrando do Programa de Pós-graduação em Educação da Universidade do Oeste de Santa Catarina.
} 
Abstract: The article presents, from a mapping, the profile of research groups in Higher Education registered in the Directory of Research of the National Council of Scientific and Technological Development (CNPq) in public universities of the southern region of Brazil. The research is bibliographical and documentary, having as historical-critical analysis methodology. The discussions contribute to identify the thematic axes that lead to the production of scientific knowledge through research in Higher Education in Brazil, highlighting as consequence the effective and much discussed idea of (re) academic productivism at a world level and its repercussions in Brazil.

Keywords: Higher education research groups. Higher education policies. Knowledge production in higher education.

Resumen: El artículo presenta, a partir de un mapeo, el perfil de los grupos de investigación en Educación Superior registrados en el Diretório de Pesquisa do Conselho Nacional de Desenvolvimento Cientifico e Tecnológico (CNPq) en universidades públicas de la región Sur de Brasil. La investigación es bibliográfica y documental, teniendo como metodología de análisis la histórico-crítica. Las discusiones contribuyen para identificar los ejes temáticos hacia los que caminan la producción del conocimiento cientifico vía investigación en la Educación Superior en Brasil, destacando como consecuencia la efectiva y tan discutida idea de (re)productivismo académico en nivel mundial y sus repercusiones en Brasil.

Palabras clave: Grupos de investigación en educación superior. Políticas de educación superior. Producción del conocimiento en la enseñanza superior.

\section{INTRODUÇÃO}

Tendo com esta pesquisa o intuito de analisar o perfil e a produção dos grupos de pesquisa na área de educação superior na região Sul do Brasil, procurase determinar quais são as investigações realmente relevantes no sentido de indagar prováveis indicadores de impacto, recepção ou utilização dos conhecimentos produzidos no meio acadêmico e social. Além disso, busca-se verificar quais áreas são repetidamente investigadas e quais são pouco estudadas no que se refere à pesquisa em educação superior.

Segundo Almeida (apud TELLO, 2013, p. 580-581), 
[...] o conhecimento científico se caracteriza por buscar uma constante busca por rigor. Tal rigor tem como objetivo, sobretudo um auto controle fundado em critérios de validez que, ao mesmo tempo, objetiva e dá a ciência parâmetros para sua evolução, além de permitir demarcar seu espaço como tal.

De acordo com a autora, o conhecimento científico, especialmente aquele diretamente ligado às políticas educacionais de ensino superior, busca um rigor que muitas vezes não se visualiza nos trabalhos da área, talvez em razão do grande número de pesquisas repetitivas e com certa ausência de critérios epistemológicos, desenvolvidos no campo das políticas educacionais do ensino superior. O fato frequentemente acarreta que sejam levantadas dúvidas sobre a validade das produções desenvolvidas nesse campo.

Para Almeida (apud TELLO, 2013, p. 586),

[...] esta ausência de critérios epistemológicos como critérios ético-políticos na pesquisa traz alguma fraqueza no processo de investigação, que em alguns casos são geradas com um ecletismo teórico em seus fundamentos, uma mistura de perspectivas que não falam umas com as outras e, em alguns casos, são até mesmo opostas.

Essa falta de fundamentação e de critérios tende a gerar dúvidas sobre a validade das pesquisas. Atualmente, no que se refere às investigações educacionais do ensino superior, percebemos bem essa realidade, uma vez que muitas áreas de estudo nesse campo se repetem. Por si só, o fenômeno acaba produzindo pesquisas sobre pesquisas já realizadas muitas vezes, sem argumentos ou questionamentos novos, e com ausência de uma base epistemológica bem definida.

Segundo Almeida (apud TELLO, 2013, p. 386),

[...] vivemos, em uma era de falta de produtividade que se vê prolongada tanto na teoria contemporânea, como esta, na cultura do simulacro; o que leva a um consequente enfraquecimento tanto nas nossas relações como na própria pesquisa no campo da política educacional.

Dessa forma, nesta pesquisa buscamos verificar qual é o perfil dos grupos de pesquisa em Educação Superior e de seus membros, refletindo sobre como se caracterizam suas produções acadêmicas, como são divulgadas e, ainda, se há um possível impacto destas em termos teóricos, políticos e práticos no Brasil. Por meio da plataforma digital <http://dgp.cnpq.br/>, procuramos realizar um levantamento 
do número de grupos de pesquisa desenvolvidos no Brasil e na região Sul do País. Investigamos, portanto, a quantidade de grupos de pesquisa estabelecidos nos três estados da região Sul, quantos pertencem a universidades públicas e, por fim, aqueles cadastrados no CNPq no censo de 2014, voltados ao campo da Educação Superior e das Políticas de Educação Superior nas universidades públicas da região Sul do Brasil.

Por intermédio desse levantamento, buscamos caracterizar a forma como se compõem os grupos de pesquisa em educação superior, suas reais dimensões, assim como relacionar quais linhas de pesquisa vêm sendo investigadas e quais têm produzido conhecimentos realmente válidos e significativos no campo do conhecimento científico. Coube, ainda, analisar a dinâmica de cada grupo de pesquisa e verificar quais se consolidam como polos da produção do conhecimento no campo da educação superior.

Nesse contexto, também procuramos indagar se os grupos de pesquisa vêm se tornando um local de formação para os novos pesquisadores, e se eles se caracterizam pela aderência de seus estudos aos objetivos aos quais suas linhas de vinculação se propõem.

Em relação ao perfil dos grupos de pesquisa, entendemos que é de grande valia saber qual o perfil, a formação, a experiência e os interesses de pesquisa de seus integrantes, principalmente quando essas informações fazem referência ao(s) líder(es) de cada grupo analisado. Nesse aspecto, consideramos importante a formação adequada do pesquisador em relação ao grupo de pesquisa ao qual se propõe liderar ou mesmo participar como pesquisador. A comprovação da não vinculação da formação dos integrantes de cada grupo de pesquisa, suas experiências e interesse de estudo ao grupo em que se inserem, poderia caracterizar a perda da validade científica de suas pesquisas e das produções provindas de tais investigações. Nesse sentido, Santos (2012, p. 8) afirma que

[...] as redes entre pesquisadores são um tema de reconhecida relevância, buscando a compreensão das condições produtoras de relações entre pesquisadores mediante o estudo das dinâmicas dessas interações no cotidiano de grupos de pesquisas, ensejando a possibilidade de se admitir a existência de auto geração e retroalimentação de conhecimento no ambiente de pesquisa. 
Nesse contexto, a formação de redes ou mesmo grupos de pesquisa se caracteriza como de extrema importância para a universidade, uma vez que é por meio destes que se desenvolvem as principais pesquisas científicas no meio acadêmico.

Segundo Bernardo (2011, p. 9), “[...] o Brasil tem sido desafiado a enfrentar questões estratégicas e complexas nas atividades de ciência, tecnologia e inovação que demandam a formação de redes de pesquisa e Pós-graduação orientadas à redução das disparidades acadêmicas regionais." Contudo, o que temos percebido no que se refere aos termos "redes" ou "grupos" de pesquisa nos últimos tempos é uma espécie de "privatização" do conhecimento. É por meio dessa "privatização" do conhecimento produzido que ocorre a sua mercantilização, criando-se mecanismos para que haja um aumento de valor do conhecimento assegurado. Esse fenômeno, por sua vez, levaria à criação de uma espécie de "pesquisa competitiva" dentro do meio acadêmico.

Segundo Almeida (2012, p. 12, grifo do autor):

Há um contraponto a esse posicionamento de se criar "pesquisa competitiva" no interior da academia, uma investigação integrada ao mercado liberal, enfim, essa nova situação que se engendra nas academias brasileiras do século XXI, acreditando que se trata de uma etapa transitória que durará até que se produza uma perfeita harmonização e conscientização do papel que se cumpre, seja ele o acadêmico, o empresarial ou o científico.

Atualmente, as universidades tendem a ser condicionadas ao contexto no qual se inserem, e seus objetivos estão ligados aos interesses de grupos organizados ou mesmo do mercado. Muitos investimentos em pesquisa realizados nos grupos pelas universidades provêm diretamente de recursos de setores empresariais, e isso nos leva a analisar questões como: até onde vai a autonomia das universidades diante desses investimentos? Até que ponto poderemos estimular uma possível integração entre universidade e contexto socioeconômico e político?

Para Almeida (2012, p. 97), a universidade “[...] ocupa uma posição central para se promover um desenvolvimento conjunto e autossustentado. É a partir dela que se pode articular um amplo programa de Pesquisa \& Desenvolvimento que contemple os variados interesses sociais." Contudo, a universidade depende diretamente de financiamentos, o que pode acabar a tornando objeto de manipulação de interesses do mercado e das demandas industriais. Em um mundo extremamente globalizado como o de hoje, exigem-se muitas mudanças e reorganizações em seu meio, o que em alguns momentos acaba por suprimir determinadas áreas de pesquisa que, economicamente, 
são consideradas inviáveis, acabando por transformá-las em uma extensão das pesquisas industriais.

Nesse sentido, conforme Almeida (2012, p. 98),

Por outro lado, a universidade pública pode se reafirmar como um centro de ressonância dos problemas nacionais, e se determinar conforme um projeto mais vasto no qual o mercado e as empresas estariam subordinadas aos interesses mais amplos de um desenvolvimento econômico não excludente internamente e não subordinado externamente.

Dessa forma, cabe a nós pensarmos um modelo de projeto para as instituições de ensino superior que busque uma maior participação das empresas em financiamentos de pesquisas e desenvolvimento, mas sem que abram mão da sua autonomia como universidades.

Segundo o censo da educação de 2014, o Brasil, hoje, possui 35.424 grupos de pesquisa cadastrados nos seguintes eixos: ciências humanas, ciências da saúde, sociais aplicadas, engenharias e computação, ciências biológicas, ciências exatas e da terra, ciências agrárias e linguística, letras e artes. Destes, a região Sul do Brasil conta atualmente com 7.938 grupos de pesquisa, como apresentamos no Gráfico 1.

Gráfico 1 - Relação entre número de grupos de pesquisa no Brasil e na região Sul

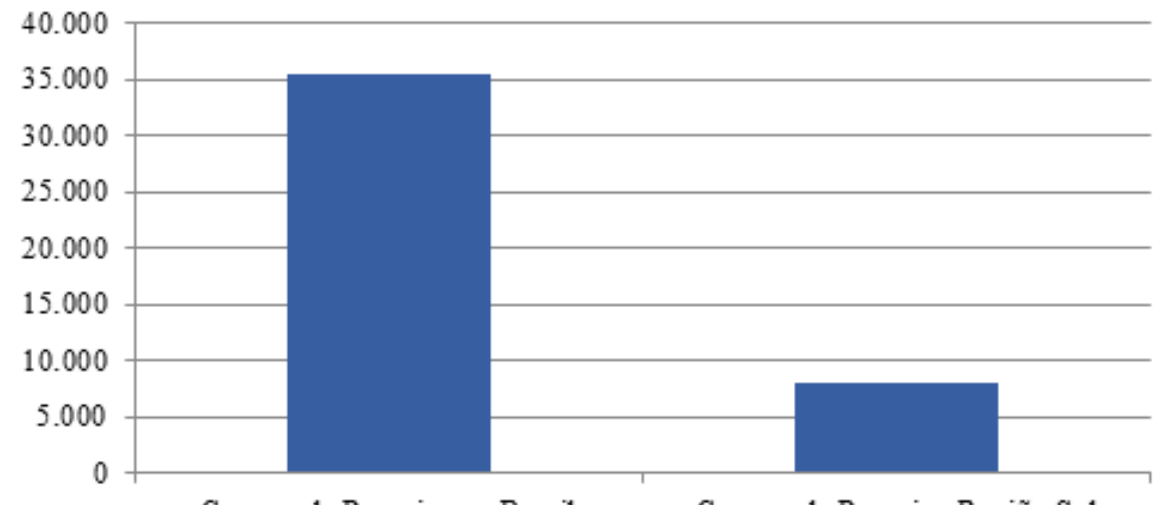

Grupos de Pesquisa no Brasil

Grupos de Pesquisa Região Sul

Fonte: adaptado do CNPq (2014).

Dos 7.938 grupos de pesquisa na região Sul, 3.315 estão sendo desenvolvidos no Rio Grande do Sul, destes, apenas 1.786 em universidades públicas; 3.011 no 
Paraná, compreendendo 2.567 em universidades públicas; e 1.612 em Santa Catarina, sendo 786 em universidades públicas, conforme demonstramos no Gráfico 2.

Gráfico 2 - Relação entre os grupos de pesquisa por estado e universidades públicas de ensino superior

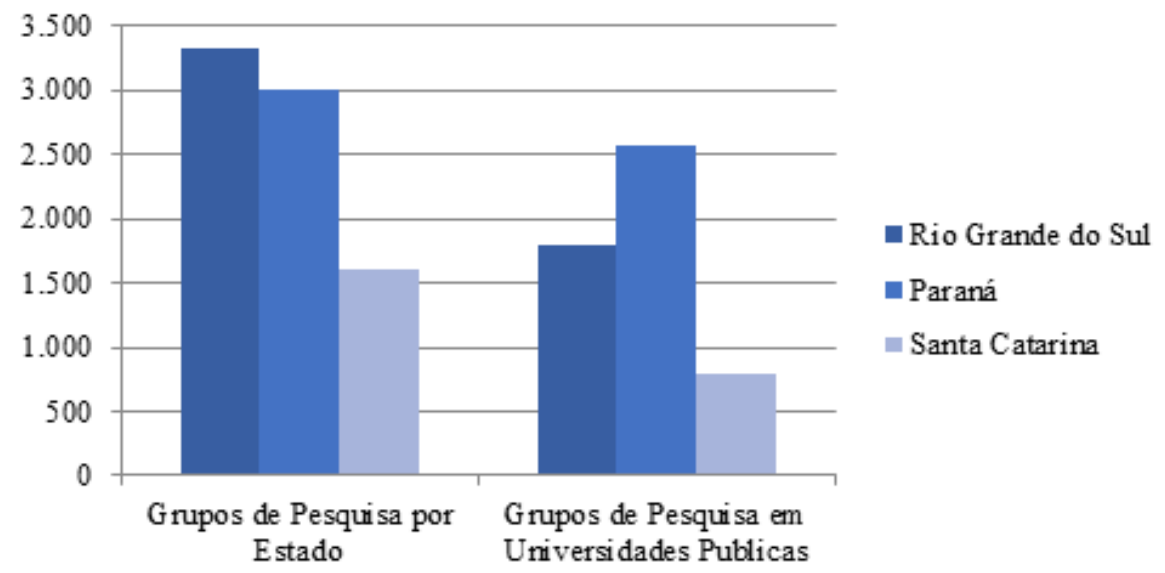

Fonte: adaptado do CNPq (2014).

Dos 2.567 grupos de pesquisa em universidades públicas do Paraná, 234 realizam seus estudos e produções no campo da educação, enquanto dos 786 grupos nas universidades públicas de Santa Catarina, 74 desenvolvem suas investigações no campo da educação. Já com respeito aos 1.786 grupos de pesquisa cadastrados no CNPq em universidades públicas do Rio Grande do Sul, 161 têm o campo da educação como área de estudo, o que totaliza 469 grupos de pesquisa no campo da Educação, como visualizamos no Gráfico 3. 
Gráfico 3 - Relação do número de grupos de pesquisa em educação localizados nas IES públicas da região Sul

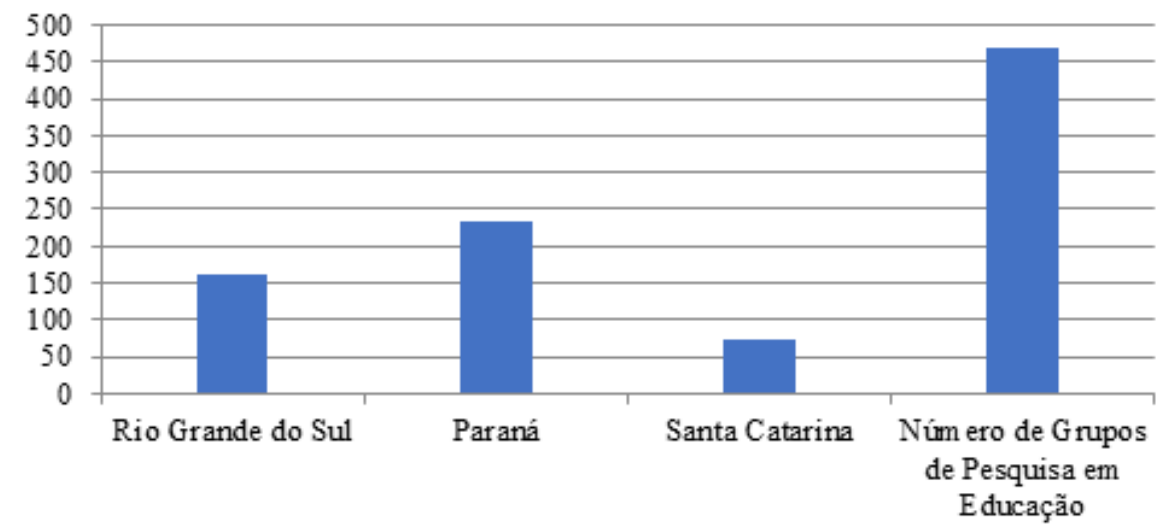

Fonte: adaptado do CNPq (2014).

Com o aprofundamento da pesquisa, verificamos que dos 234 grupos de pesquisa em universidades públicas do Paraná, dois são voltados à educação superior, enquanto dos 74 grupos nas universidades públicas de Santa Catarina três deles desenvolvem suas investigações no campo da educação superior. Já no que se refere aos 161 grupos de pesquisa cadastrados no CNPq em universidades públicas do Rio Grande do Sul, cinco tomam a educação superior como área de estudo, como podemos visualizar no Gráfico 4.

Gráfico 4 - Grupos de pesquisa em educação superior em universidades públicas da região Sul

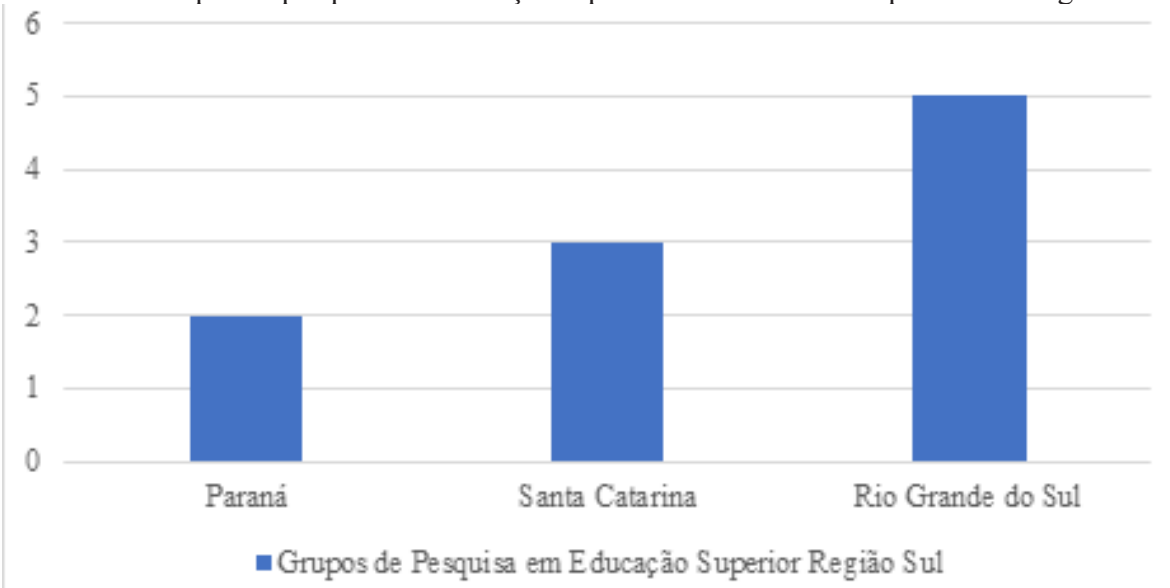

Fonte: adaptado do CNPq (2014). 
Considerando os dados apurados, visualizamos que no Estado do Paraná, somando os grupos de pesquisa em Educação com suas bases construídas nas universidades públicas, apenas $0,85 \%$ realizam suas pesquisas no campo da educação superior. Para o percentual de Santa Catarina, temos 4,05\% dos grupos em universidades públicas investigando no âmbito da educação superior. Quanto aos dados do Estado do Rio Grande Sul, 3,10\% dos grupos de pesquisa voltados à educação realizam seus estudos especificamente no âmbito da educação superior em universidades públicas. Analisando tais dados, podemos perceber o quão vaga e deficitária é a pesquisa acadêmica no que se refere à área da educação superior como campo de estudo e reflexão, e, partindo desse pressuposto, consideramos esses números alarmantes.

Entendendo que é de grande valia debater essas questões, nos propomos, a seguir, a analisar os grupos de pesquisa em educação superior localizados nos três estados da região Sul do Brasil: Paraná, Santa Catarina e Rio Grande do Sul. O intuito com essa análise foi verificar quais as linhas de pesquisa que os grupos seguem, quem são seus líderes, quais são os impactos de suas pesquisas e, principalmente, se elas abrangem as reais necessidades do contexto social em que as universidades se inserem, ou vêm simplesmente atender aos seus próprios interesses ou de terceiros.

\section{PRODUÇÃO DO CONHECIMENTO CIENTÍFICO NOS GRUPOS DE PESQUISA EM EDUCAÇÃO SUPERIOR NO PARANÁ}

Atualmente, o Estado do Paraná conta com 10 universidades públicas credenciadas no CNPQ, a saber: Universidade Federal do Paraná (UFPR), Universidade Estadual de Londrina (UEL), Universidade Tecnológica Federal do Paraná (UTFPR), Universidade Estadual de Maringá (UEM), Universidade Estadual do Oeste do Paraná (Unioeste), Universidade Estadual de Ponta Grossa (UEPG), Universidade Estadual do Centro-Oeste (Unicentro), Universidade Estadual do Norte do Paraná (Unespar), Universidade Estadual do Paraná (UEPR) e Universidade Federal da Integração Latino-Americana (Unila). As Instituições possuem 2.567 grupos de pesquisa credenciados no CNPQ. Contudo, quando observamos o número de grupos de pesquisa desenvolvidos pelas universidades públicas paranaenses em relação aos grupos voltados à educação superior, vemos que apenas dois têm como campo de 
debate a educação superior. Esses grupos se encontram, por sua vez, instituídos na Universidade Federal do Paraná (UFPR) e na Universidade Estadual do Oeste do Paraná (Unioeste), como podemos observar nos Quadros 1 e 2.

Quadro 1 - Grupo de pesquisa em educação superior desenvolvido na Universidade Federal do Paraná

\begin{tabular}{|c|c|c|}
\hline Grupo de Pesquisa & Líderes & Linhas de Pesquisa \\
\hline $\begin{array}{l}\text { Saberes e Práticas } \\
\text { no Ensino Superior }\end{array}$ & $\begin{array}{l}\text { Prof. Dra. Tânia Maria Bai- } \\
\text { bich; } \\
\text { Prof. Dra. Blanca Beatriz Díaz } \\
\text { Alva. }\end{array}$ & $\begin{array}{l}\text { Didática e Metodologia do Ensino } \\
\text { Superior; } \\
\text { Relações de poder e preconceito; } \\
\text { Ética e formação de professores. }\end{array}$ \\
\hline
\end{tabular}

Fonte: os autores.

O grupo de pesquisa Saberes e Práticas no Ensino Superior, desenvolvido na Universidade Federal do Paraná (UFPR), tem como líderes as professoras doutoras Tânia Maria Baibich e Blanca Beatriz Díaz Alva. A primeira tem formação na área Psicologia pela Universidade Federal do Rio Grande do Sul (1980), mestrado em Educação pela Universidade Federal do Paraná (1986), doutorado em Psicologia Social pela Universidade de São Paulo (2001), pós-doutorado em Preconceito na Escola na Universidade de Michigan (2003) e em Pedagogia do Ensino Superior na Universidade do Vale do Rio dos Sinos (2008).

A segunda docente possui licenciatura em Ciências Sacras pelo Instituto Pontifício Regina Mundi (Roma, 1971), especialização em Mariologia pela Faculdade Pontifícia Teológica Marianum (Roma, 1971), bacharelado e licenciatura em Educação pela Pontifícia Universidade Católica do Peru (1980), mestrado (1990) e doutorado (1999) em Educação pela Universidade Estadual de Campinas. O grupo desenvolve pesquisas nas linhas Didática e metodologia do ensino superior, Relações de poder e preconceito e Ética e formação de professores, caracterizando-se por ser constituído de pesquisadores que se dedicam ao estudo de questões relacionadas aos saberes e práticas escolares no ensino superior desde 1997. Seus resultados de pesquisas vêm sendo apresentados por meio de eventos científicos, além de já defendidas dissertações de mestrado e teses de doutorado. Destacam-se como publicações mais recentes do grupo: $O$ desenho e o diálogo: alfabetização do aluno no ateliê de projeto arquitetônico (ORTEGA; BAIBICH, 2013) e Educação Superior em Direitos Humanos face a ideologia neoliberal globalizada (ALVA, 2014, p. 115-130). Por 
meio da análise desse grupo de pesquisa, observamos que suas linhas, assim como a proposta de investigação, estão de acordo com a formação acadêmica e com as experiências e práticas de trabalho e pesquisa de suas líderes.

Quadro 2 - Grupo de pesquisa em educação superior desenvolvido na Universidade Estadual do Oeste do Paraná

\begin{tabular}{|l|l|l|}
\hline Grupo de Pesquisa & Líderes & Linhas de Pesquisa \\
\hline Grupo de Estudos & Profa. Dra. Carmen Celia Bar- & \\
e Pesquisas sobre & radas Correia Bastos; & Formação Docente; \\
Educação Superior & Profa. Ms. Elenita Conegero & Políticas de Educação Superior. \\
(GEPES) & Pastor Manchope. & \\
\hline
\end{tabular}

Fonte: os autores.

O grupo de pesquisa denominado Grupo de Estudos e Pesquisas sobre Educação Superior (GEPES) está sediado na Universidade Estadual do Oeste do Paraná (Unioeste) e possui duas líderes: a professora doutora Carmen Celia Barradas Correia Bastos, graduada em Pedagogia pela Universidade Federal do Piauí (1980), mestre (1989) e doutora (2004) em Educação pela Universidade Estadual de Campinas. Ela possui experiência na área de Educação.

A outra líder é a professora mestre Elenita Conegero Pastor Manchope, com graduação em Pedagogia (1991) e mestrado em Educação (2002), ambos pela Universidade Estadual de Maringá. Tem experiência na área de Educação. O grupo de pesquisa realiza seus estudos norteados por duas linhas, a saber: Formação docente e Políticas de educação superior. É filiado ao Grupo de Estudos e Pesquisas em Educação da Unicamp, o qual foi criado em 28 de outubro de 1992, tendo como função principal a realização de estudos e pesquisas sobre a educação superior, particularmente a brasileira, com vistas a analisar com rigor, por meio dos estudos e pesquisas realizados no GEPES, as grandes questões que as universidades enfrentam atualmente.

\section{MAPEAMENTO DOS GRUPOS DE PESQUISA EM EDUCAÇÃO SUPERIOR EM SANTA CATARINA}

O Estado de Santa Catarina contempla, segundo o censo de 2014 realizado pelo CNPq, um total de 786 grupos de pesquisa, os quais desenvolvem suas investigações em duas universidades federais: a Universidade Federal de Santa Catarina (UFSC) e a Universidade Federal da Fronteira Sul (UFFS) e, ainda, em 
uma universidade estadual: a Universidade Estadual de Santa Catarina (Udesc). Em relação ao número de grupos de pesquisa encontrados nas universidades públicas catarinenses é importante salientar que, apesar da elevada quantidade, observamos que apenas um se dedica à pesquisa no campo da educação superior, como podemos observar no Quadro 3.

Quadro 3 - Grupo de pesquisa em educação superior desenvolvido na Universidade Federal de Santa Catarina

\begin{tabular}{|l|l|l|}
\hline Grupo de Pesquisa & Líderes & Linhas de Pesquisa \\
\hline Trabalho e conheci- & Prof. Dr. Lucídio & Políticas Públicas para a Educação Superior; \\
mento na educação & Bianchetti; & Produção do Conhecimento, Interdisciplina- \\
(Traces) & Prof. Dr. Juares da & ridade e Tecnologia; \\
& Silva Thiesen. & Trabalho e Educação; \\
& & Trabalho, Educação e Tecnologia. \\
\hline
\end{tabular}

Fonte: os autores.

Denominado Grupo de Pesquisa Trabalho e conhecimento na educação superior (Traces), o grupo tem como sede a Universidade Federal de Santa Catarina (UFSC). Seu líder é o professor doutor Lucídio Bianchetti, que possui graduação em Pedagogia com habilitação em Orientação Educacional pela Universidade de Passo Fundo (1978), mestrado em Educação pela Pontifícia Universidade Católica do Rio de Janeiro (1982), doutorado em Educação, História, Política e Sociedade pela Pontifícia Universidade Católica de São Paulo (1998), e Estágio pós-doutoral na Universidade do Porto, Portugal (2009). Tem experiência na área de Educação. O outro líder é o também professor e doutor Juares da Silva Thiesen, graduado em Estudos Sociais pela Universidade do Oeste de Santa Catarina (Fundeste) (1987) e em Geografia pela Universidade do Oeste de Santa Catarina (Unoesc) (2000). Mestre em Educação - Ensino Superior pela Fundação Universidade Regional de Blumenau (FURB) (1995) e doutor em Ciências Pedagógicas pelo Instituto Central de Ciências Pedagógicas (ICCP), Havana/Cuba (2002) (Título revalidado no Brasil pelo Parecer n. 209/CPG/2006 de 14/12/06 da Universidade Federal de Santa Catarina (UFSC), e doutor em Engenharia e Gestão do Conhecimento pela Universidade Federal de Santa Catarina (UFSC) (2009). Possui experiência na área de Educação.

Por meio das linhas de pesquisa: Políticas públicas para a educação superior, Produção do conhecimento, interdisciplinaridade e tecnologia, Trabalho e educação e Trabalho, educação e tecnologia, o grupo pretende compreender o 
processo de produção e a disseminação do conhecimento ancorando-se nas discussões sobre a intensificação do trabalho na atualidade profissional, enfatizando as condições de trabalho dos profissionais da educação superior, especialmente da pós-graduação. Nesse contexto, dedica especial atenção à compreensão das categorias temporalidade e autonomia da atualidade e às consequências que acarretam as inovações tecnológicas e organizacionais nos processos de trabalho e no trabalho intelectual que se produz na universidade.

Conforme afirma Bianchetti (2001, p. 48-49), “[...] nada se compara ao papel estratégico atribuído à informação nestes últimos anos, nos quais é clara a supremacia do capital financeiro. Hoje além do aspecto político, a valorização econômica da informação é cada vez mais evidente." A informação, então, ou mesmo a produção do conhecimento, passa a ter função central no mundo capitalista de acumulação de bens e de capital, protagonizando a mão de obra. Dessa maneira, o próprio profissional da educação torna-se comercializável na medida em que se despende dos reais objetivos de sua pesquisa para satisfazer aos interesses daqueles que a financiam.

\section{LEVANTAMENTO DOS GRUPOS DE PESQUISA EM ENSINO SUPERIOR NO RIO GRANDE DO SUL}

Conforme o censo de 2014, o Estado do Rio Grande do Sul possui hoje um total de cinco universidades públicas: Universidade Federal do Rio Grande do Sul (UFRGS), Universidade Federal de Santa Maria (UFSM), Universidade Federal de Pelotas (UFPel), Universidade Federal do Rio Grande (Furg) e Universidade Federal do Pampa (Unipampa). Entre as universidades gaúchas foram encontrados 1.786 grupos de pesquisa em desenvolvimento, dos quais cinco têm como objetivo a pesquisa do campo de estudo da educação superior.

Quadro 4 - Grupo de pesquisa em educação superior da Universidade Federal do Pampa

\begin{tabular}{|c|c|c|}
\hline Grupo de Pesquisa & Líderes & Linhas de Pesquisa \\
\hline $\begin{array}{l}\text { Grupo de estudos e } \\
\text { pesquisa em inclusão } \\
\text { e diversidade na } \\
\text { educação básica e no } \\
\text { ensino superior }\end{array}$ & $\begin{array}{l}\text { Profa. Dra. Francéli } \\
\text { Brizolla; } \\
\text { Profa. Dra. Claudete da } \\
\text { Silva Lima Martins. }\end{array}$ & $\begin{array}{l}\text { Ensino e aprendizagem na perspectiva } \\
\text { inclusiva; } \\
\text { Formação de professores na perspectiva } \\
\text { inclusiva; } \\
\text { Política e gestão da educação na pers- } \\
\text { pectiva inclusiva. }\end{array}$ \\
\hline
\end{tabular}

Fonte: os autores. 
O Grupo de estudos e pesquisas em inclusão e diversidade na educação básica e no ensino superior possui como sede a Universidade Federal do Pampa (Unipampa) e sua instituição parceira de pesquisa é a Universidade Federal do Rio Grande do Sul (UFRGS). O grupo tem como líderes as professoras doutoras Francéli Brizolla e Claudete da Silva Lima Martins, tendo a primeira graduação em Educação Especial pela Universidade Federal de Santa Maria (1997), mestrado e doutorado em Educação (2000 e 2007) na área de política e gestão da educação, por meio do Programa de Pós-Graduação em Educação pela Universidade Federal do Rio Grande do Sul (UFRGS). A segunda possui doutorado em Educação na linha de Formação Docente do Programa de Pós-Graduação em Educação da Faculdade de Educação da Universidade Federal de Pelotas (UFPel), mestrado em Educação pela mesma universidade, duas especializações relacionadas às modalidades de Educação Especial realizadas na Universidade da Região da Campanha (Urcamp) e Universidade Federal de Santa Maria (UFSM), graduação em Pedagogia pela Universidade da Região da Campanha e experiência na área da Educação.

Quanto às linhas que norteiam as pesquisas do grupo, observamos que são três: Ensino e aprendizagem na perspectiva inclusiva, Formação de professores na perspectiva inclusiva e Política e gestão da educação na perspectiva inclusiva. Como principais repercussões, apresenta a produção de conhecimento na perspectiva da educação inclusiva e do atendimento à diversidade, o aprimoramento das possibilidades de implementação de atendimento educacional especializado na educação básica e superior, o fortalecimento da rede de trabalho colaborativo entre a educação básica e o ensino superior na perspectiva inclusiva.

Quadro 5 - Grupo de pesquisa em educação superior da Universidade Federal do Rio Grande

\begin{tabular}{|l|l|l|}
\hline Grupo de Pesquisa & Líderes & Linhas de Pesquisa \\
\hline Rede de estudos & Profa. Dra. Gionara & Epistemologia e formação docente; \\
e pesquisas em & Tauchen; & Inovação e produção do conhecimento; \\
educação superior & Profa. Dra. Catia Piccolo & Políticas de Educação Superior; \\
(REPES) & Viero Devechi. & Docência na educação superior. \\
\hline
\end{tabular}

Fonte: os autores.

Sediado na Universidade Federal do Rio Grande (FURG), o grupo de pesquisa Redes de estudos e pesquisas em educação superior (REPES) é liderado pela 
professora doutora Gionara Tauchen, a qual possui graduação em Pedagogia (UFSM), mestrado em Educação (UFSM), doutorado em Educação (PUC/RS) e Pós-doutorado em Ensino-aprendizagem na Universidade Eduardo Mondlane (UEM), Moçambique.

O grupo é liderado também pela professora doutora Catia Piccolo Viero Devechi, graduada em Pedagogia com habilitação em pré-escola pela Universidade Federal de Santa Maria (2001), mestrado em Educação pela mesma universidade (2004) e doutorado em Educação pela Universidade Federal de Santa Catarina (2008). Conta com experiência na área da Educação.

Por meio de suas líderes, o grupo desenvolve estudos nas linhas: Epistemologia e formação docente, Inovação e produção do conhecimento, Políticas de educação superior e Docência na educação superior.

Constata-se, a partir desses dados, que ambas as professoras possuem graduação na área de Pedagogia e especialização no campo da educação, tendo experiências em comum, principalmente na área da formação de professores e nos temas de pesquisa desenvolvidos por meio de suas linhas, o que gera um caráter de maior validade no que se refere às investigações realizadas pelo grupo.

Conforme o Quadro 6, a Universidade Federal de Santa Maria (UFSM) tem vinculados atualmente ao CNPq três grupos de pesquisa que desenvolvem suas investigações no macro campo de pesquisa da educação superior: Políticas, avaliação e gestão no ensino superior, Formação de professores e práticas educativas: educação básica e superior (GPFOPE) e Avaliação no ensino superior.

Quadro 6 - Grupos de pesquisa em educação superior da Universidade Federal de Santa Maria

\begin{tabular}{|l|l|l|}
\hline Grupo de Pesquisa & Líderes & Linhas de Pesquisa \\
\hline $\begin{array}{l}\text { Políticas, avaliação e ges- } \\
\text { tão no ensino superior }\end{array}$ & $\begin{array}{l}\text { Prof. Dr. Francisco Nilton } \\
\text { Gomes de Oliveira. }\end{array}$ & - \\
\hline $\begin{array}{l}\text { Formação de professores } \\
\text { e práticas educativas: } \\
\text { educação básica e superior } \\
\text { (GPFOPE) }\end{array}$ & $\begin{array}{l}\text { Profa. Dra. Doris Pires } \\
\text { Vargas Bolzan; } \\
\text { Profa. Dra. Silvia Maria de } \\
\text { Aguiar Isaia. }\end{array}$ & $\begin{array}{l}\text { - Formação de professores e } \\
\text { práticas educativas: educação } \\
\text { básica e superior; } \\
\text { - Formação docente e desenvol- } \\
\text { vimento profissional: educação } \\
\text { básica e superior. }\end{array}$ \\
\hline $\begin{array}{l}\text { Avaliação no ensino } \\
\text { superior }\end{array}$ & $\begin{array}{l}\text { Profa. Dra. Glades Tereza } \\
\text { Felix; } \\
\text { Profa. Dra. Fabiane Adela } \\
\text { Tonetto Costas. }\end{array}$ & - Avaliação no ensino superior. \\
\hline
\end{tabular}

Fonte: os autores. 
O primeiro grupo, denominado Grupo de Pesquisa Políticas, avaliação e gestão no ensino superior, é liderado pelo professor doutor Francisco Nilton Gomes de Oliveira, graduado em Terapia Ocupacional pela Universidade de Fortaleza (1997), mestre em Psicologia também pela Universidade de Fortaleza (2001), doutor em Linguística pela Universidade Federal de Pernambuco (2010) e Pós-Doutor em Educação pela Universidade Federal do Rio Grande do Sul (UFRGS).

Por meio da análise dos dados do CNPq (2014) percebemos que o grupo tem como objetivo central criar uma rede de discussão interinstitucional em nível nacional e internacional sobre políticas, avaliação e gestão superior. Contudo, os dados do grupo não são atualizados na base de dados do $\mathrm{CNPq}$ há um período de quase dois anos, e também não possui linha alguma de pesquisa que venha a nortear suas investigações, ou mesmo estudos. Outro fator interessante é que o líder do grupo somente teve formação na área da educação a partir da realização do seu pósdoutorado em educação na Universidade Federal do Rio Grande do Sul (UFRGS).

Considerando os fatores que nos propomos a analisar com esta pesquisa, entendemos que esse conjunto de informações faz com que, tanto o grupo de pesquisa quanto suas próprias investigações, percam em relação aos critérios de validade, confiabilidade e legitimidade em relação ao campo de estudos ao qual se propõe.

Por sua vez, o Grupo de Pesquisa denominado Formação de professores e práticas educativas: educação básica e superior (GPFOPE) é liderado por duas docentes: a professora doutora Doris Pires Vargas Bolzan, pedagoga pela Universidade Federal do Rio Grande do Sul (1986), Especialista em Psicopedagogia Terapêutica pelo Centro de Estudos Médicos e Psicopedagógicos de Porto Alegre (1989), mestre em Educação (1995) e doutora em Educação (2001) pela Universidade Federal do Rio Grande do Sul (UFRGS). Tem experiência em pesquisas de temáticas voltadas à educação; e a professora doutora Silvia Maria de Aguiar Isaia, graduada em Filosofia (1973), mestre em Filosofia (1981) pela Universidade Federal de Santa Maria e doutora em Educação (1992) pela Universidade Federal do Rio Grande do Sul, tem experiência na área de Educação.

O grupo possui duas linhas de pesquisa: Formação de professores e práticas educativas: educação básica e superior e Formação docente e desenvolvimento profissional: educação básica e superior. Por meio delas, realizam suas investigações nos temas: aprendizagem permanente da docência - seja inicial, seja continuada -, 
pedagogia universitária, cultura escrita, alfabetização, leitura e escrita, conhecimento pedagógico compartilhado, resiliência docente, alternância pedagógica, atividade docente de estudo, atividade discente de estudo e trabalho pedagógico.

Por meio da realização de uma análise do grupo, verificamos que ambas as líderes possuem formação acadêmica e experiências profissionais diretamente ligadas ao campo de estudo ao qual o grupo se propõe. Devemos salientar que há uma forte presença do tema formação de professores também no grupo de pesquisa GPFOPE, assim como na formação das líderes do grupo.

O grupo de pesquisa Avaliação no ensino superior é liderado pela professora doutora Glades Tereza Felix e pela professora doutora Fabiane Adela Tonetto Costas, sendo a primeira graduada em Pedagogia, Licenciatura Plena, pela Universidade de Federal de Santa Maria (UFSM) em 1982, mestre em Educação também pela (UFSM) em 1993, doutora em Educação (UFRGS) em 2008 e pós-doutora (UFRGS) em 2012 em Acreditação e Avaliação. A segunda possui formação em Pedagogia, com habilitação em Séries Iniciais e Matemática pela Universidade Federal de Santa Maria (UFSM) no ano 1990, mestre em Educação também pela Universidade Federal de Santa Maria (1996), doutora em Educação pela Universidade Federal do Rio Grande do Sul (UFRGS) em 2003 e pós-doutora pela Universidade do Minho, Portugal. Pesquisa e realiza estudos na área de educação.

Tendo como única linha de pesquisa a Avaliação no ensino superior, vem se caracterizando por produzir inúmeras atividades como a reativação e a reorganização da Comissão de Avaliação do Centro de Educação (CE) da UFSM, além de elaborar projetos de pesquisa, ensino, extensão e eventos, constituindo o Programa de Avaliação Institucional do CE/UFSM (PAICE). Publicou e divulgou até 2008 o periódico Avaliação em Revista, apresentando os resultados da auto avaliação do CE. Em 2013, publicou pela editora da UFSM a obra Avaliação Institucional e Ação Política: múltiplas realidades na educação superior, em parceria com pesquisadores de países como Uruguai, Argentina, Angola, Portugal e Brasil. Em 2013, promoveu o ciclo de debates sobre Avaliação Institucional no âmbito do CE, no qual foi oportunizada a discussão da importância da qualidade no ensino superior.

Considerando esses fatores, além de suas produções, constata-se que as pesquisas realizadas pelo grupo se constituem como de grande valia para o campo da educação como um todo, dando ênfase especial à educação superior. 


\section{CONSIDERAÇÕES FINAIS}

Por meio desta pesquisa foram buscados grupos de pesquisa voltados à investigação no campo de estudo do ensino superior e das políticas de ensino superior. Como fruto do estudo, encontramos oito grupos de pesquisa voltados ao macro campo da educação superior, que se enquadram tanto na área da educação superior quanto das políticas de educação superior, nas universidades públicas na região Sul do Brasil. Os grupos encontram-se assim distribuídos: dois no Estado do Paraná, sendo um na Universidade Federal do Paraná (UFPR) e um na Universidade Estadual do Oeste do Paraná (Unioeste); um no Estado de Santa Catarina, localizado na Universidade Federal de Santa Catarina (UFSC); e cinco no Estado do Rio Grande do Sul, sendo um na Universidade Federal do Pampa (Unipampa), um na Universidade Federal do Rio Grande (FURG) e três na Universidade Federal de Santa Maria (UFSM).

A partir da análise é possível inferir que vivemos em um momento no qual a produção em massa é constantemente estimulada pelos órgãos financiadores de pesquisas acadêmicas, como a Coordenação de Aperfeiçoamento de Pessoal de Nível Superior (Capes), CNPq e órgãos privados, considerando-se a quantidade e não a qualidade das produções. Dessa forma, colocamos com receio os dados analisados em relação aos grupos de pesquisa em educação superior desenvolvidos nas universidades públicas na região Sul do Brasil.

Embora tenham nomenclaturas diferentes, observa-se que os grupos de pesquisa embasam e orientam suas pesquisas em três linhas comuns: Formação de professores, Políticas de educação superior e Produção do conhecimento. Outro fator importante a destacar é a relação que as linhas de pesquisa possuem com o trabalho docente: Didática e metodologia do ensino superior, Ética e formação docente, Trabalho e educação, Epistemologia e formação docente, Docência no ensino superior e Avaliação no ensino superior.

Por meio da análise dos grupos, percebemos um expressivo número de publicações realizadas e o fato de os líderes, quase na sua totalidade, terem formação em relação direta com a área da educação. O que se observa é uma repetida preocupação em propor pesquisas no campo da formação de professores. Contudo, considerando as políticas para formação de professores e para o ensino superior, entendemos que elas não conseguem atender aos debates voltados à educação superior na atualidade. 
Por meio dos dados analisados, não vemos um debate aberto sobre as políticas de educação superior para além da formação de professores, embora os grupos busquem pesquisar no sentido da produção do conhecimento. A produção do conhecimento entendemos que deva ser considerada em um sentido amplo, debatendo a formação de professores, mas perguntando qual é o papel do docente perante um sistema que se constitui cada vez mais como um formador de mão de obra para o mercado, moldada para simplesmente executar e não questionar.

Nesse sentido, muito antes de pesquisar a simples formação do professor, temos que formar o pesquisador que busca entender os processos e as políticas traçadas pela educação superior brasileira, com o intuito de questioná-la e, a partir daí, entender qual é o real papel do professor na atualidade, que é o de formar cidadãos pesquisadores e questionadores, que consigam visualizar algo a mais, além do que o que mercado capitalista pede e impõe.

Outro fator que nos preocupa quanto aos grupos de pesquisa voltados à educação superior é o elevado número de pesquisas na área da formação superior e o alto risco que essas produções possuem de se repetir, uma vez que o campo de estudo é o mesmo, o que acarretaria uma desvalorização quanto aos trabalhos acadêmicos na área, considerando que, embora sejam pesquisas de grupos diferentes, poderíamos chegar a conclusões parecidas ou praticamente iguais.

No que se refere ao grupo de pesquisa voltado às políticas de educação superior denominado Políticas, avaliação e gestão no ensino superior observou-se que ele não possui linhas de pesquisa que norteiam as investigações do grupo, além do fato de não ser atualizado há um período de aproximadamente dois anos na base de dados do CNPq. Outro fator que devemos considerar é que o líder do grupo não possui formação na área da educação, mas, sim, na área da saúde, o que de certa forma colocaria em "xeque" a validade das pesquisas do grupo, uma vez que a formação do líder não possui aderência ao campo de pesquisa.

De modo geral, consideramos que os grupos de pesquisa encontrados, com exceção do grupo Políticas, avaliação e gestão no ensino superior, localizado na Universidade Federal de Santa Maria (UFSM), estão com suas investigações diretamente relacionadas às linhas às quais se propõem, além de seus líderes possuírem aquiescência quanto à sua formação e atuação aos referidos grupos e linhas que coordenam. 


\section{REFERÊNCIAS}

ALMEIDA, M. L. P. de. A pesquisa acadêmica no Século XXI: uma análise da ciência frente aos conceitos de público e privado. Campinas: Mercado de Letras, 2012.

ALMEIDA, M. L. P. de. Enfoque para el análisis de investigaciones em política educacional In: TELLO, C. (Org.). Epistemologías de la política educativa: posicionamentos, perspectivas y enfoques. Campinas: Mercado de Letras, 2013.

ALVA, B B. D. A Educação Superior em Direitos Humanos face a ideologia neoliberal globalizada. Revista Interdisciplinar de Direitos Humanos, Bauru, v. 2, n. 2, p. 115-130, jun. 2014.

BERNARDO, D. B. O Programa Nacional de Cooperação Acadêmica Novas Fronteiras: avaliação de progresso e oportunidades para o futuro. 2011. 122 p. Dissertação (Mestrado Acadêmico em Educação)-Universidade Federal do Rio Grande do Sul, Porto Alegre, 2011.

BIANCHETTI, L. Da Chave de Fenda ao Laptop, Tecnologia Digital e Novas Qualificações: desafios à educação. Petrópolis: Vozes; Florianópolis: Ed. UFSC, 2001.

DIRETÓRIO de Pesquisa do Conselho Nacional de Desenvolvimento Científico e Tecnológico (CNPq). Censo nacional dos grupos de pesquisa 2014. Disponível em: <http://dgp.cnpq.br/dgp/>. Acesso em: 14 nov. 2015.

ORTEGA, A. R.; BAIBICH, T. M. O desenho e o diálogo: alfabetização do aluno no ateliê de projeto arquitetônico. In: REUNIÃO NACIONAL DA ANPED, 36., 2013, Rio de Janeiro. Anais... Rio de Janeiro, 2013.

SANTOS, E. O. da P. Redes de Pesquisadores: instrumentos pedagógicos para a sua formação e consolidação. 2012. 164 p. Dissertação (Mestrado Acadêmico em Educação e Contemporaneidade)-Universidade do Estado da Bahia, Salvador, 2012.

Recebido em: 07 de março de 2017 Aceito em: 31 de maio de 2017

Endereço para correspondência: Rua Getúlio Vargas, 2125, Flor da Serra, 89600000, Joaçaba, Santa Catarina, Brasil; malu04@gmail.com 